risks of walking the streets or taking the tram, provided community, meaning, an opportunity for patriotism, and a consequent protection from stress that staying safely at home could not.

In addition the framework of post-traumatic stress disorder cannot encompass the wide range of people's psychosocial experiences and needs in this situation. How, for example, can one find the time and space and acknowledgement of private grief in the context of massive collective loss? Nor does it help in distinguishing what is appropriate behaviour and what is pathological behaviour. Every day from my office window I watched students crossing the most dangerous street in the town, to reach the philosophy faculty, in full view and easy range of Serbian snipers. Were they exhibiting a courageous determination to continue normal life or unhealthy, life threatening denial?

And the social workers with whom I worked repeatedly reminded me, as I sat in their crowded, shattered, and freezing offices in various parts of the city, that the majority of their psychological problems could be wiped out tomorrow if my own government would use its political and military muscle to lift the seige of the city. Indeed the most prominent psychological symptoms I encountered were exhaustion at the prospect of a third winter of war and bewilderment at the Western stereotype of Bosnians as Muslim funda- mentalists. "You have seen the orthodox and catholic churches in this city," said Dr Semir Bešlija, my colleague of Catholic Relief Services. "Tell me where one mosque remains in the territory controlled by Karadzić? What kind of fundamentalism is that?" Throughout the population I encountered growing feelings of frustration, betrayal, and incomprehension at the failure of the West to understand the dangers of appeasing fascist aggression and anger at the denial of the basic right to self defence. "We have to act for ourselves," Professor Cerić told me, "because the international community does nothing." He keeps a cartoon above his desk, in which an elegantly dressed young woman addresses a psychiatrist: "I have neither illusions nor delusions, Doc, my problem is that I exist day after day in grim reality."

During the two months I spent in Sarajevo last autumn, what I had to offer in the field of mental health was welcomed and valued, but the insistence that I understand the political and social context from which the psychological problems arose reminded me yet again of my own responsibilities for prevention as well as cure.

1 Summerfield D. The impact of war and atrocity on civilian populations: an overview of major themes. In: Black D, Harris, Hendricks G, Mezey G, Newman M, eds. Psychological trauma: a developmental approach. London: Royal College of Psychiatry, Gaskell (in press).

\title{
Management for Doctors
}

\section{Handling the conflicting cultures in the NHS}

\author{
James Drife, Ian Johnston
}

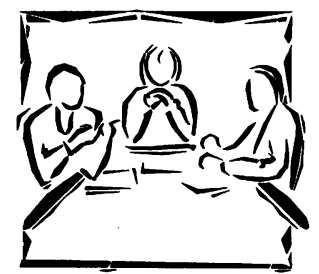

This is the last in a series of articles dealing with issues arising as clinical practitioners increasingly take on managerial roles. The series is edited by fenny Simpson, chief executive, British Association of Medical Managers. $A$ book of the series is now available from the BMF Bookshop.

Department of Obstetrics and Gynaecology, University of Leeds, Leeds LS2 9NS

James Drife, professor

General Infirmary, Leeds LS1 3EX

Ian Johnston, director of

hospital services

Correspondence to:

Professor Drife.

BMF 1995;310:1054-6

\section{Case study: working to contract}

St Duncan's and St Kenneth's United Hospitals Trust, like other hospitals, is now funded by contracts which specify how much work is to be undertaken in each specialty or subspecialty. Like many hospitals in the real world outside London, the trust has only one major purchasing authority. In the case of one specialty, ontological surgery, the volumes set for the contract are reasonable but tight. The ontological surgeons (all men, incidentally) have always run an excellent service, including giving dates for admission within a few months to outpatients. During the year they have improved on their already impressive performance, and waiting times for admission are now a matter of weeks. The problem with this is that the hospital is now well ahead of contract
The NHS is a multicultural society. Each professionmedical, nursing, management, and many others-has its own identity, culture, and subcultures. Within medicine there are various specialty groupings, such as surgeons, psychiatrists, or general practitioners, with different characteristics and aims. The potential for conflict arising from cultural differences is almost limitless-a problem not, of course, unique to the NHS. ${ }^{1}$ This article focuses as an example on the relationship between NHS managers and doctors and concentrates on conflict and its resolution. The overall relationship is a much richer subject than can be addressed here and it has been well discussed by Harrison $^{2}$ as well as by other authors in this series.

The tension between the amount of clinical work that could be done and the amount of money available to pay for it has always been present in the NHS. The recent reforms have highlighted the differences and the health authority can afford to pay only for the agreed contract volumes. The health authority has also said that if it did have more money it would want to use it in specialties that were having difficulty with waiting lists.

The managerial culture requires, broadly, that the contract numbers are adhered to, and the consultants have been required to restrict their activities. The doctors, however, know that there are patients waiting for treatment. They want to treat them and they believe that the health authority's problems are not theirs. They feel that if other specialties have excessive waiting lists they should be required to get their house in order before being given extra funds. The managers and the doctors have reached an impasse. between medical and management responses to this tension.

To handle this conflict successfully, each group needs to understand the other's culture. Often they think they do, but what understanding they have may be based on stereotype and often tends to reinforce rather than reduce antagonism.

\section{The managers' view}

From the managers' perspective this matter may seem eminently clear. The contract volumes have been agreed and therefore have to be maintained. Despite much opinion to the contrary, managerial life is not as simple as that. Managers are public servants and take their responsibilities to the public seriously. They know that someone has to take on the task of ensuring that all the demands of politicians, doctors, patients, 
therapists, nurses, etc, are balanced and health care is delivered as equitably as possible.

The hospital managers know that life is more complicated than the ontological surgeons allow. The managers, like the surgeons, are on the patients' side but they also know that choices have to be made and priorities agreed. Unfettered developments in ontology will lead to problems for the patients of other specialties-apparently beyond the immediate concerns of the ontological surgeons.

The managerial perspective does indeed accept that contracts have to be kept. What kind of world would it be if they were routinely flouted? How could any hospital survive and flourish if its key staff ignored what had been agreed? From this point of view the failure lies squarely with the consultants for not planning their work for the year. It cannot be denied that not only is such planning possible but these consultants are good at it.

\section{"The potential for conflict arising from cultural differences is almost limitless."}

Any manager must recognise what has been achieved by the consultants. From the patients' and the general practitioners' point of view this specialty is a success. The managerial perspective also requires that the service's users remain satisfied. It will be of no benefit to the hospital if such a highly successful service is seen as being curtailed or cut. The manager understands that except for the use of draconian measures it is only through the cooperation of the consultants that any change to this service can occur. (For an analysis of control mechanisms and clinical freedom, see Harrison. ${ }^{3}$ )

Yet action must be taken. The hospital cannot do work for which it is not paid. To allow the present position to continue in this specialty would lead to financial difficulties. If no action is taken here other specialties will follow suit and the whole hospital will face financial crisis.

\section{The doctors' view}

The ontological surgeons know that working to contract means treating fewer patients than they want to treat, and therefore either working less during the normal week or stopping completely as the end of the financial year approaches. They find this unacceptable because of their traditional work ethic and because they want to help people. In the main, general practitioners address referral letters not to the manager but personally to the consultant. A deterioration in the hospital service harms the surgeon's reputation, which has taken years to build up.

More altruistically, he feels angry on the patient's behalf. He has found that prompt service usually surprises his patients, who expect to queue for NHS treatment and rarely complain if they are forced to wait. The consultants feel that they alone are responsible for maintaining good standards. This leads to the "mother tiger" syndrome, with a ferocious doctor trying to protect the interests of docile patients.

The ontologists are not convinced that the hospital will suffer if they continue to work. The biggest cost in a hospital is the staff. Surgeons, anaesthetists, and nurses are not being made redundant; the beds are there and the ward is being heated and lit. Why, then, will an operation that uses relatively little consumable material cost the accountant so much money? The surgeons feel the accountant's perception has little to do with real life.

Doctors feel aloof from imperatives that affect managers. Regarding themselves as being at the apex of the hospital hierarchy, they are not overawed by top management. They see contracts and purchaserprovider arrangements as an irrelevance. Even if the entire NHS collapses, their clinical work will continue because a new system will be created around them.

The ontological surgeons feel they have the support of colleagues in other professions. The operating theatre, despite being a mixture of cultures, works like a military unit. The bonding in a surgical team can be as strong as that in a platoon in battle-while it is under attack from a common enemy. Relationships between the cultures may be complex in the team but the team unites against perceived threats from outside.

\section{Handling the conflict}

There are many ways in which conflict between cultures can be handled. ${ }^{14}$ At one extreme is the use of power to assert the rightness of one approach over the other. This is generally tactfully deployed, but this method of resolving conflicts is nevertheless quite common. However, in a complex and changing environment like the NHS, where allies will always be needed in future conflicts, it is more common to see such approaches reduced to compromise. The "deals" which conflicting parties reach are a tacit recognition that no profession or culture is totally dominant. Resolution of conflict in this way is always incomplete: more deals will be needed before too long.

It is a fact of life that most conflict is "handled" and little is resolved. Differences create progress and organisations which manage conflict constructively are the ones that make the greatest progress. ${ }^{5} \mathrm{We}$ are optimistic about the possibilities. Most conflicts as they occur day to day in the NHS could be resolved if the will and understanding were really there. The fact that they are not reflects a general belief that this is not possible and that the cultures in the NHS are irresolvably in conflict. In particular, the belief is becoming entrenched that conflict between managers and doctors is somehow an intrinsic part of the NHS.

\section{"Even if the entire NHS collapses, [doctors'] clinical work will continue because a new system will be created around them."}

We believe this is neither desirable nor necessary. What are the steps out of eternal conflict?

\section{STEP 1: MUTUAL RESPECT}

The first essential is mutual respect between the parties-that is, an acceptance of the legitimacy of the separate cultures and an acceptance that other people really do hold to their beliefs as strongly as you. To achieve this needs time, effort, and communication skills. You can accept another culture only if you understand it, and you cannot understand it if you stay locked within your own culture and simply reinforce your own prejudices. Doctors and nurses talk to each other every day; even so, cultural misunderstanding persists. It is rare for doctors and managers to enjoy lunch or a tea break together, except at formal meetings. It is essential to allow sufficient time for this informal interaction. 
STEP 2: SHARED VALUES

Following mutual acceptance, it is possible to define the values which both cultures share. ${ }^{6}$ This requires tenacity, as discussions between managers and doctors tend to gravitate towards areas of disagreement. All too often each party seizes on inconsistencies in the other's statements, and discussion sometimes resembles the presentations of opposing counsel in court-but with no judge to arbitrate. Keeping the discussion focused on shared values means stating these values explicitly and honestly, and restating them as often as necessary.

In the present case what can be shared is a desire to provide good care, and for the hospital to thrive as a whole. Political beliefs can be acknowledged but must not be allowed to polarise local discussions. Neither doctors nor managers want to turn the ontology service into a political football. Both recognise that they have to work within a democracy, and that the democratic process legitimately leads to changing requirements from its health care system.

STEP 3: HONESTY

Discussions between managers and doctors have for years been characterised by poker playing. Each side takes up a negotiating position but has a fallback position which is what it usually expects. This can lead doctors into shroud waving and overbidding for equipment, and cause managers to overstate the size of the hospital's overdraft. Sooner or later the bluff is

\section{"One way of stimulating frank discussion is to breach etiquette by putting the hidden agenda on the table."}

revealed and from then on neither group believes a word the other says. The problem with lying as routine has been well illustrated by Aesop in his fable about the boy who cried wolf. We suggest that it is time to learn this 2500 year old lesson. Honesty is the best policy, even when doctors and managers meet.

\section{STEP 4: SHARED OBJECTIVES}

On the basis of values which both cultures share it is then possible to agree shared objectives about the way forward. (For a framework of values and its relationship to organisation development, see Kinston.') The first step is to discuss all possible hidden objectives. One way of stimulating frank discussion is to breach etiquette by putting the hidden agenda on the table. Do the managers want to make a point about who is in charge of the hospital? Do the surgeons want to provoke a public confrontation so as to involve the electorate at large in the debate about NHS funding? If these threatening options are made explicit they can be examined objectively. After discussion they are likely to be rejected.

The doctors and managers can then agree short term and medium term objectives. In the case study the short term objective will be agreement on the immediate workload and the medium term objective is to decide the level of next year's contract. In the long term, who knows? - perhaps sharing values and agreeing objectives will provide the foundations to deal with whatever changes occur to the NHS in the future.

\section{Key point summary}

- Mutual respect is essential between management and clinicians and other health care professionals

- Shared values need to be expressed explicitly and honestly, and frequently restated

- Shared objectives need to be identified

- Disinformation should be combated

STEP 5: COMBATING DISINFORMATION

Once initial agreement is reached by representative groups, they must convince their sceptical colleagues - that is to say, the values and objectives must be truly shared. Hospital gossip tends to reduce issues to simplistic conflict and, unfortunately, in many places conflict has more credibility than consensus. Managers' cheerful newsheets are often perceived as propaganda and have to be backed up by word of mouth. A modern hospital, like 18th century London, is a coffee house culture, and mutual respect and shared values cannot survive for long if they are undermined by off the record chat. Both doctors and managers, having emerged with consensus from a constructive discussion, may be tempted to impress their respective peers by claiming a victory against the old enemy, thus reducing the danger of their being seen as traitors to their own culture. A little of this may be necessary to avoid cultural isolation, but more than a little is counterproductive and undermines any progress made.

\section{Conclusion}

Our steps may seem to be compromise with a different hat on. They are, however, conceptually very different. Compromise is based on the balance of power and is therefore unstable because power relations change. The approach we are advocating is based on values, and values endure. It applies not only to doctors and managers but to other cultures within the NHS, all of which-despite their conflicts-share similar enduring values.

1 Handy CB. On politics and the management of differences. In: Understanding organisations. 3rd ed. Harmondsworth: Penguin, 1998:222-56.

2 Harrison S. Managing the NHS: shifting the frontier? London: Chapman and Hall, 1988.

3 Harrison S. The frontier of control. In: Managing the NHS: shifting the frontier? London: Chapman and Hall, 1988:1-8.

4 Mintzberg H. Power in and around organisations. New York: Prentice-Hall, 1983.

5 Lickert R. The principles of supportive relationships. In: Pugh DS, ed. Organisation theory-selected readings. Harmondsworth: Penguin, 1987: 293-316.

6 Kinston W. Strengthening the management culture. London: Sigma Centre, 1994.

$7 \mathrm{Kinston} W$. The rationalist mode. In: Strengthening the management culture. London: Sigma Centre, 1994:43-53.

\section{Correction}

The number needed to treat: a clinically useful measure of treatment effect

An authors' error occurred in this article by Richard J Cook and David L Sackett (18 February, pp 452-4). In the table the event rate for moderate hypertension in the control group should be 0.02 and not 0.2 , leading to a number needed to treat of 125 [not 13]. 